\title{
The Rise in Long-Term Unemployment: Potential Causes and Implications
}

Andreas Hornstein and Thomas A. Lubik

$\mathrm{T}$

he dramatic rise in long-term unemployment has been one of the most striking features of the Great Recession of 2007-09. The number of unemployed workers who have been out of a job for more than half a year has reached heights that the U.S. economy has not witnessed since the Great Depression.

The overall unemployment rate has been elevated for a substantial period of time, although it has not reached its post-World War II peak of 10.8 percent. Underlying this dire unemployment picture is the rise in long-term unemployment and an overall lengthening of the duration of unemployment spells, which are now far above their levels in previous recessions.

The U.S. labor market historically has been characterized by relatively short unemployment durations for an average worker. The high level of long-term unemployment we are currently seeing represents a sharp break with previous experiences. In the past, most job losses led to only short unemployment spells, as the labor market was able to quickly absorb newly unemployed workers into employment relationships. Although some workers, in particular older ones, experienced long periods of unemployment, the incidence of long-term unemployment in the United States was far less than in other OECD countries. Moreover, although recessions have always been characterized by lengthening unemployment spells, a quick increase in hiring when

\footnotetext{
- The authors would like to thank Marianna Kudlyak, Jessica Romero, Aaron Steelman, John Weinberg, and Alexander Wolman for discussions and detailed comments and Nika Lazaryan for excellent research assistance. The views expressed are those of the authors and not necessarily those of the Federal Reserve Bank of Rich- mond or the Federal Reserve System.
}

DOI: http://doi.org/10.21144/eq1010203 
coming out of a recession kept the incidence of long-term unemployment low. The Great Recession seems to be different in that respect.

The high level of unemployment, in combination with a high fraction of long-term unemployment, presents challenges for both monetary and fiscal policymakers. Many of the efforts of the Federal Reserve were aimed at halting the decline in output and employment in the wake of waves of adverse shocks. Arguably, the Fed's policies were successful in that respect. However, the U.S. economy has been operating under extremely low nominal interest rates for such an extended period that additional expansionary monetary actions, such as quantitative easing, are possibly only marginally effective.

In this article we discuss how long-term unemployment has become such a dominant feature of the labor market during the Great Recession. We first summarize the data on aggregate unemployment and the duration distribution of unemployment for the United States since 1960. We then show that, in terms of pure accounting, the composition of the unemployment pool is determined by the inflow and outflow of workers, that is, by the rates at which workers lose and find jobs. We begin from an aggregate perspective and argue that the increase in long-term unemployment can largely be explained by a decline in the exit rate from unemployment. The severity of the recession led to high initial job losses, but the persistent and substantial increase in unemployment and unemployment duration is mainly due to a decline in job finding rates. In response to the increase in long-term unemployment, Congress extended the maximum duration of unemployment benefits from six months to close to two years. We discuss the effects of this extension on unemployment duration and argue that the effects have been limited.

We then proceed to a more disaggregate analysis and study how unemployment of different demographic groups was affected by the Great Recession. We show that unemployment rates and duration differ substantially across demographic groups, but that almost all groups were equally affected by the increase in unemployment rates and duration. We then discuss how negative duration dependence, that is, the apparent decline in job finding rates with the length of time unemployed, affects long-term unemployment. We find that accounting for duration dependence allows us to better model long-term unemployment in the U.S. labor market. This accounting framework also suggests that a significant part of the increase in long-term unemployment is indeed due to the inflow into unemployment of workers with relatively low job finding rates. We conclude by arguing that given the increased contribution to overall unemployment of unemployed workers with inherently low job 
finding rates, monetary policymakers may want to exercise caution in the use of policy to respond to the level of unemployment.

\section{A LOOK AT THE DATA}

The standard measure of unemployment comes from the monthly Current Population Survey (CPS) conducted by the Census Bureau for the Bureau of Labor Statistics. This survey, commonly known as the household survey, is a randomly selected sample of about 60,000 households that report on their employment status and other characteristics. ${ }^{1}$

A respondent is classified as employed, unemployed, or out of the labor force. A respondent is classified as unemployed if he or she reports not being employed but is actively searching for a job. The labor force is defined as those respondents who are either employed or unemployed, and respondents who are neither employed nor actively searching for a job are classified as being out of the labor force. The unemployment rate is the ratio of the number of unemployed respondents to the number of workers in the labor force. Conditional on the employment state, there are follow-up questions that further characterize the employment state. Employed respondents are asked about the type of employment (part-time or full-time), their occupation, and the industry of employment, among other questions. Unemployed respondents are asked about the length of the ongoing unemployment spell and their previous occupation and industry. Basic demographic information is also collected, such as the sex, age, race, and education level of the respondent. ${ }^{2}$

There are two notable features to the pattern of the rise and fall of unemployment over the business cycle. First, unemployment rises

\footnotetext{
${ }^{1}$ The Bureau of Labor Statistics provides a detailed description of the CPS at http://www.bls.gov/cps/.

${ }^{2}$ We can look at the household survey as providing information on the supply of labor. There are two other surveys that report on the state of the U.S. labor market from the demand side for labor.

The Current Employment Statistics (CES) program, commonly known as the establishment survey, reports on the number of jobs from a sample of about 440,000 establishments in the U.S. nonfarm sector. By construction, the establishment survey provides information on employment only, not unemployment. Furthermore, the establishment survey provides information on jobs and not on household employment. For example, a household survey respondent who works two jobs is counted as employed once, but the establishment survey would count two jobs. Finally, the establishment survey does not cover unincorporated self-employment.

Another recently introduced survey, the Job Openings and Labor Turnover Survey (JOLTS), tries to capture how establishments change their employment. JOLTS provides monthly data on job openings, hires, quits, layoffs, etc., for a sample of about 16,000 establishments.

More detailed descriptions of the CES and JOLTS are provided at http://www.bls.gov/ces/home.htm and http://www.bls.gov/jlt/home.htm, respectively.
} 


\section{Figure 1 Long-Term Unemployment}

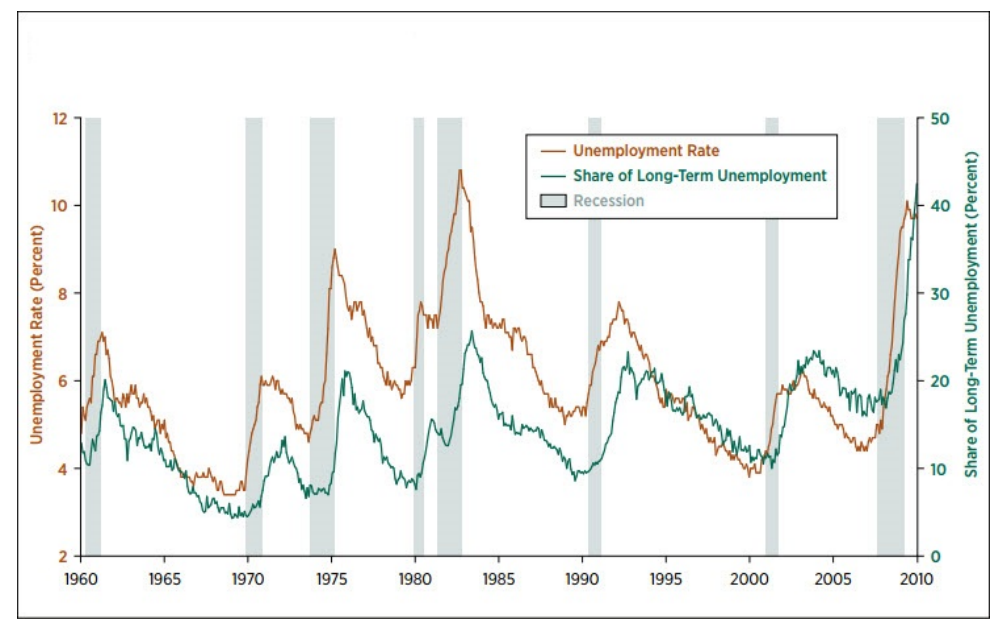

Sources: Bureau of Labor Statistics, Haver Analytics, authors' calculations.

Notes: The share of long-term unemployment (more than 26 weeks) as a percent of total unemployment typically increases during recessions (the shaded areas). But following the most recent recession, the share is nearly double the previous peak after the 1981-82 recession.

rapidly at the onset of a recession, but it comes down only slowly over the course of the recovery. Second, long-term unemployment increases sharply with overall unemployment.

Figure 1 depicts the unemployment rate (dark orange line, left axis) and the share of total unemployment that is long-term unemployment (green line, right axis) for the U.S. economy from 1960 through 2010, with recessions highlighted in grey. ${ }^{3}$ The average unemployment rate for this period is about 6 percent, but unemployment increases substantially in recessions. For example, in the 1981-82 recession the unemployment rate increased by about three percentage points within

\footnotetext{
${ }^{3}$ The recessions are dated using the business cycle peaks and troughs as announced by the National Bureau of Economic Research (NBER). NBER business cycle dates are a widely accepted definition of recessions in the United States. The NBER procedure to date the beginning and end of a recession is supposed to reflect a widespread and significant decline in economic activity. As such, the NBER procedure incorporates a large number of measures of economic activity, including production, sales, income, and employment. Unemployment tends to lag the NBER recession dates, in the sense that the unemployment rate peaks after the end of the recession. For more detailed information on the NBER business cycle program, see http://www.nber.org/cycles/main.html.
} 
one and a half years to reach a peak of 10.8 percent in October 1982 . In the expansion phase, the unemployment rate then usually declines slowly from its peak. This pattern is especially noticeable for the 199091 recession and the 2001 recession, and has given rise to the idea of a "jobless recovery," in which economic growth picks up, but employment gains are small and unemployment declines only slowly. This pattern seems to be repeating itself in the current recovery.

Long-term unemployment is defined as being unemployed for more than 26 weeks. This is the conventional measure of long-term unemployment since unemployment benefits typically last for about half a year. In Figure 1 we see that the average share of long-term unemployment is quite low, about 15 percent from 1960 to 2010, but in every recession the share of long-term unemployment increases sharply with the unemployment rate. A similar observation applies to the mean duration of unemployment for all those who report job search durations in any month. From 1960 to 2010 the average mean duration of unemployment is about 14 weeks, but mean duration increases significantly in recessions.

The increase in unemployment during the Great Recession stands out for its severity, especially the substantial increase in long-term unemployment. Unemployment peaked at 10.1 percent in October 2009, about one quarter after the official end of the recession according to the National Bureau of Economic Research (NBER) dating scheme, and stayed close to this level for almost one year. For the postwar period, this peak unemployment rate is second only to the 10.8 percent unemployment rate after the 1981-82 recession. The share of long-term unemployment peaked at 46 percent in the second quarter of 2010, and averaged a bit more than 43 percent for all of 2010. This peak value for the share of long-term unemployment is significantly higher than the previous peak of 26 percent that was attained following the 198182 recession. Finally, mean duration of unemployment had increased to about 35 weeks by the middle of 2010, again a substantial increase over the previous peak for mean unemployment duration of 21 weeks after the 1981-82 recession. Never before in the postwar period have unemployed workers been unemployed for such a long time.

\section{ACCOUNTING FOR UNEMPLOYMENT}

We now take a more systematic look at how total unemployment is related to unemployment duration. For this purpose we study how the inflows into unemployment and the outflows from unemployment determine total unemployment. One can think of total unemployment as the water level in a bathtub, which is determined by the inflow of 
new water and the rate at which the water drains. The total number of unemployed workers is determined by the rate at which workers become newly unemployed and start looking for work (the entry rate) and the rate at which current unemployed workers find work (the exit rate). ${ }^{4}$ Other things being equal, the more workers who become newly unemployed, that is, the higher the entry rate, then the higher the total number of unemployed workers. Similarly, at a given inflow rate of newly unemployed workers, the less likely it is that an unemployed worker finds a new job, then the higher the total number of unemployed workers will be eventually. For a slightly more formal representation of this model see Box 1.

While total unemployment depends on both the entry and exit rates, the average duration of unemployment depends mainly on the behavior of the exit rate. The lower the exit rate, that is, the lower the chance that an unemployed worker becomes employed, then the longer the average unemployment duration and the larger the share of workers who have been unemployed for a long time.

Robert Shimer (2007) shows how one can recover measures of the entry and exit rate from data on total unemployment and data on shortterm unemployment, that is, workers who have been unemployed for fewer than five weeks. ${ }^{5}$ The maintained assumption of his accounting exercise is that all unemployed workers are homogeneous in the sense that they all have the same exit rate. This is a simplifying assumption that provides some valuable first insight into the dynamics of unemployment and the interpretation of long-term unemployment. We will relax that assumption below.

Since the increase in the unemployment rates during recessions is usually accompanied by a substantial lengthening of unemployment duration, a declining exit rate must be an important source of high unemployment. In other words, it is hard to find a job during recessions. This observation also suggests that more long-term unemployment does not necessarily mean that the long-term unemployed are in any way different from the short-term unemployed. Even if all unemployed workers face the same exit rate, a decline in the exit rate will

\footnotetext{
${ }^{4}$ Given the definition of unemployment, workers may exit unemployment not only because they find work, but also because they stop searching, that is, the workers drop out of the labor force. Alternatively, they may enter unemployment not only because they lose a job, but also because they decide to (re)enter the labor force and search for a job. In the analysis we disregard the flows in and out of the labor force. For most purposes this is not a restrictive assumption (Shimer 2007).

${ }^{5}$ Similar exercises have been performed by Elsby, Michaels, and Solon (2009) and Fujita and Ramey (2009). An important debate in this literature concerns the relative importance of variations in the job finding rates and the job separation rates in accounting for variations of the unemployment rate.
} 
Figure 2 Duration Dependence in Exit Rates

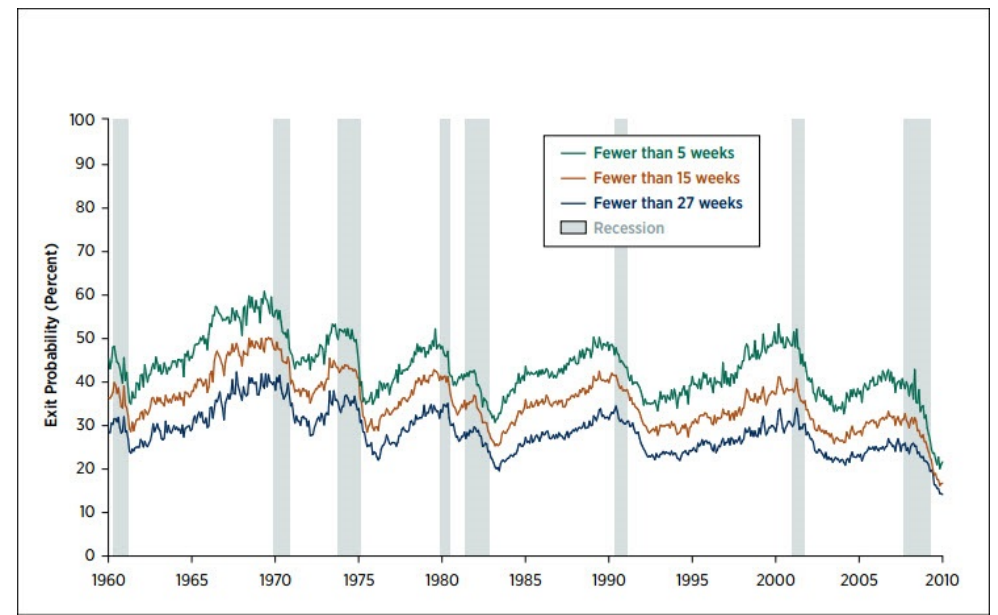

Sources: Bureau of Labor Statistics, Haver Analytics, authors' calculations.

Notes: Workers who have been unemployed for fewer than five weeks have the highest probability of exiting unemployment within the next month. The likelihood of exit typically declines for all workers during recessions (the shaded areas), but it continued to decline well after the troughs of the last three recessions.

yield higher average unemployment duration and an increased share of long-term unemployment.

We follow Shimer's (2007) simple accounting framework and recover entry and exit rates of homogeneous unemployed workers. In Figure 2 we display the implied exit rates of workers who have been unemployed for fewer than 5 weeks, fewer than 15 weeks, and fewer than 27 weeks. The green line displays the exit rate from unemployment implied by data on short-term unemployment, that is, those workers who have been unemployed for fewer than 5 weeks. ${ }^{6}$ Most of the time unemployed workers find a job quite quickly: the average probability that an unemployed worker finds work within a month is about 40 percent, and at the peak of an expansion this job finding probability can be as high as 60 percent. As we also can see, the exit rate from

\footnotetext{
${ }^{6}$ The exit rates displayed in Figure 2 are actually derived from the steady state relationship between unemployment duration shares and the exit rate as described in Box 1. We also calculate exit and entry rates using data on short-term unemployment while not imposing the steady state condition as in Shimer (2007). With a few exceptions the two procedures essentially yield the same series for the exit rate.
} 
unemployment drops sharply in a recession, falling to about 35 percent in previous recessions. Furthermore, in the jobless recoveries after the 1990-91 recession and the 2001 recession, the exit rate from unemployment declined significantly even two years after the recessions' troughs. The 2007-09 recession again stands out in terms of the speed and magnitude of the decline in the exit rate from unemployment. One year after the trough, the probability of finding a job within a month declined to about 20 percent, about half the average exit rate from unemployment and substantially less than in previous recessions.

A model with homogeneous unemployment is consistent with the qualitative features of long-term unemployment in recessions, but it cannot account for the magnitude of long-term unemployment in recessions. Using the entry and exit rates from our unemployment accounting exercise, we can construct counterfactual duration distributions for unemployment. By construction, the parameters of the simple model exactly match total unemployment and the number of workers unemployed for fewer than 5 weeks. A model with homogeneous unemployed workers is not a good match for medium- and long-term unemployment, however. Consistent with the data on previous recessions, the model does predict a sharp rise in medium- to long-term unemployment in recessions. But the model significantly understates the magnitude of long-term unemployment: for almost all recessions the model predicts only one-third of those workers who are unemployed for more than 26 weeks.

\section{THE EFFECTS OF UNEMPLOYMENT INSURANCE ON UNEMPLOYMENT}

We use the share of unemployed workers who have been unemployed for more than 26 weeks as a measure of long-term unemployment. As noted above, the particular cutoff duration for this conventional definition of long-term unemployment is related to the maximum duration of unemployment benefits, usually 26 weeks. Unemployment compensation programs are administered at the state level, and the amount and duration of benefits may vary across states. The duration of unemployment compensation tends to increase in response to increased unemployment following a cyclical downturn. These changes occur at the state and federal level. In particular, in response to the increase in long-term unemployment in 2008, in June of that year Congress authorized an Emergency Unemployment Compensation (EUC) program that provided an additional 13 weeks of benefits for unemployed workers who were eligible under state programs. After various additional authorizations, by early 2010 the maximum duration of unemployment benefits 
was 99 weeks, with some variation across states. For a description of the different programs, see Daniel Aaronson, Bhashkar Mazumder, and Shani Schechter (2010).

The duration of unemployment benefits is extended in order to lessen the negative impact of unemployment on long-term unemployed workers. A side effect of extended benefits can be to lengthen the average duration of unemployment. If we assume that unemployed workers make choices about whether to accept or reject job offers, then increasing or extending unemployment benefits will affect how these choices are made. On the one hand, unemployed workers who are currently eligible for unemployment benefits may be willing to hold out for longer until they receive what they think is a more acceptable offer. This will reduce the exit rate from unemployment for these workers and thereby increase the average duration of unemployment. On the other hand, not every unemployed worker qualifies for unemployment benefits. In order to qualify, a worker must have had a job and must have been laid off. If a worker does not qualify for unemployment benefits, lengthening the duration of unemployment benefits does not mean much for the worker now, but it does make taking a job much more attractive since the worker then qualifies for the extended unemployment benefits should the worker become unemployed again. Thus one might expect that unemployed workers who are ineligible for unemployment benefits become more willing to accept job offers if unemployment benefits are extended.

There is a considerable amount of empirical work on the possible effects of extended unemployment benefits on unemployment duration. Aaronson et al. (2010) and Michael Elsby, Bart Hobijn, and AyŞegül Şahin (2010) survey that work and provide some estimates on how the EUC program may have affected the duration of unemployment. They start with estimates that an extension of unemployment payments by one week tends to increase unemployment duration by 0.1 to 0.2 weeks. Considering that the duration of unemployment benefits has been increased by up to 73 weeks, and that only about 50 percent of unemployed workers are eligible for unemployment benefits, they estimate that the EUC program may have lengthened the average duration of unemployment by between 2 and 6 weeks. This is a significant lengthening, but much less than the actual 18-week increase of average unemployment duration from about 17 weeks in 2008 to 35 weeks in the middle of 2010. Furthermore, as Aaronson et al. (2010) and Elsby et al. (2010) point out, the lower bounds of their estimates are likely to be more relevant than the upper bounds. Finally, using the simple bathtub model of unemployment, one can translate the estimated 
increase in unemployment duration to an increase in the unemployment rate of between one and three percentage points. ${ }^{7}$

\section{DIFFERENT UNEMPLOYMENT EXPERIENCES}

The previous discussion considers only the behavior of total unemployment in the economy. But the labor market experience in the United States is not the same for all members of the labor force. Unemployment rates differ vastly across demographic groups. For instance, as of December 2010 the unemployment rate among individuals who have not completed high school was more than three times the unemployment rate of those with a college degree. It is therefore tempting to hypothesize that some of the higher unemployment and the longer unemployment duration might be due to composition effects. This term describes the idea that during a recession the composition of newly unemployed workers shifts toward demographic groups characterized by lower exit rates and longer durations. In other words, the overall unemployment picture hides deeper dynamics in the labor market that affect specific groups, occupations, or industries in markedly different ways.

In Table 1 we show the average unemployment rate, mean duration of unemployment, and share of long-term unemployment for several demographic groups for the available sample after 1960 and for the year 2010. Three things are apparent: First, unemployment rates and unemployment durations differ significantly across demographic groups. Second, during the 2007-09 recession, unemployment tended to increase more in some groups that in the past were less susceptible to job loss in recessions. Third, for all demographic groups, unemployment rates, mean durations of unemployment, and long-term unemployment shares are significantly higher than their sample averages prior to the recession. While the first two observations point to the possibility that changes in the composition of unemployment inflows might contribute to the overall increase in unemployment, the third observation suggests that changes in composition cannot be a complete explanation for the overall increase in unemployment.

\footnotetext{
${ }^{7}$ This estimate is based on the relationship between mean unemployment duration and the exit rate from unemployment described in Box 1. The calculations are conditional on an average monthly job separation rate of 3 percent per month (Shimer 2007). A similar exercise is performed by Mazumder (2011).
} 


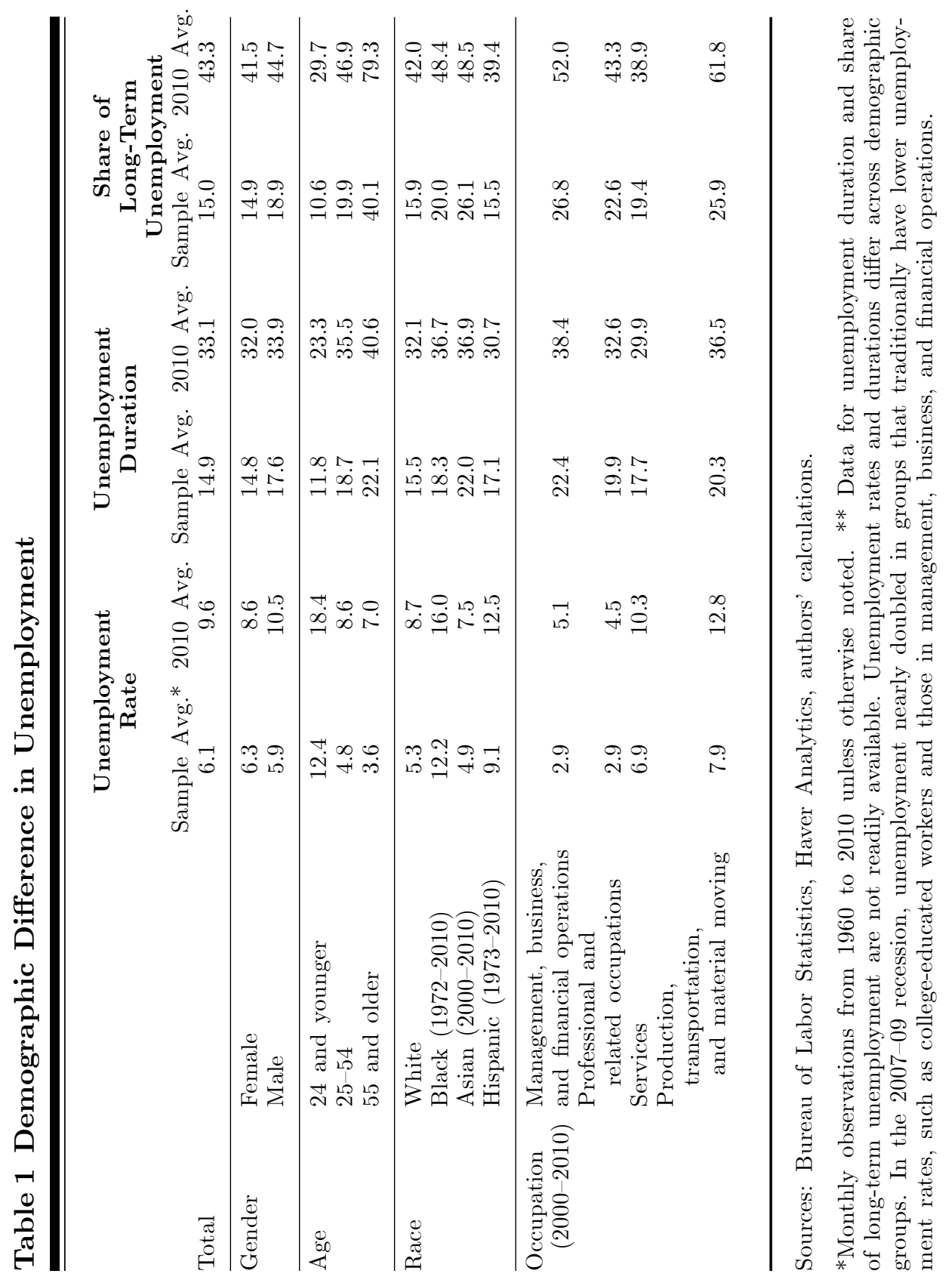




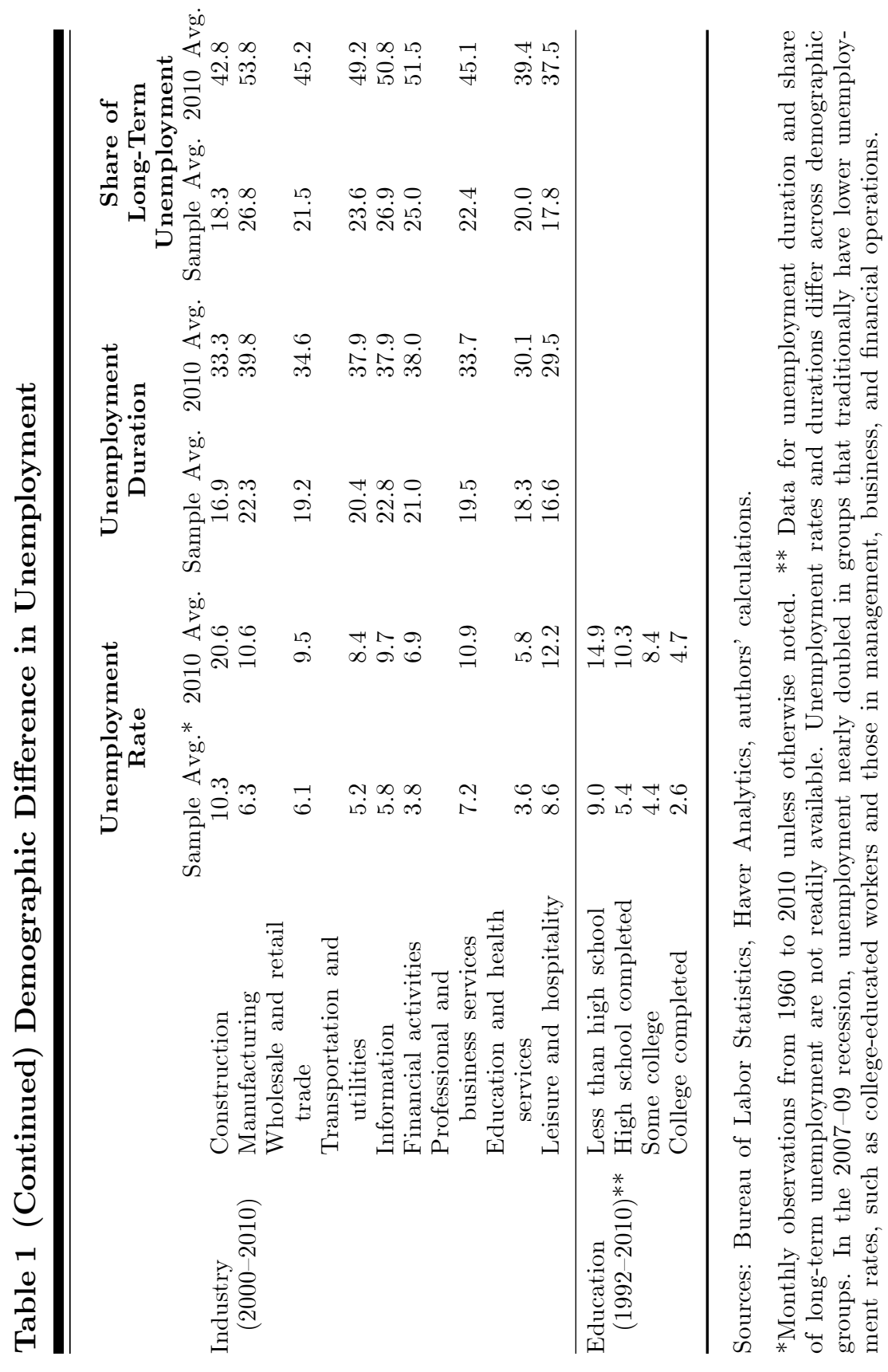


The average unemployment rate in 2010 was more than 50 percent higher than the average unemployment rate from 1960 through 2010. Although the unemployment rate of males tends to be somewhat lower than the unemployment rate of females, in 2010 the unemployment rate of males increased relative to that of females. Across age groups, the unemployment rate of younger workers (under 25) tends to be higher than that of older workers (over 55), but in 2010 the unemployment rate of older workers increased relative to that of younger workers. ${ }^{8}$ Overall, the unemployment rate of workers who have not completed high school is about three times as high as that of workers with a college degree, yet in 2010 the unemployment rate of college-educated workers increased slightly relative to that of workers without a high school degree. Workers in managerial occupations related to business and financial operations have some of the lowest unemployment rates among all occupations, certainly compared to service-oriented occupations and occupations in the production sector, but in 2010 the unemployment rate for managerial occupations increased somewhat relative to these other occupations. ${ }^{9}$ Across industries, the average unemployment rate in construction in 2010 was nearly three times the rate in financial activities, but in both industries the rate almost doubled over the sample average. Since construction and financial services were at the heart of the 2007-09 recession, it should not be too surprising that workers affiliated with both industries experienced some of the biggest increases in unemployment rates.

The differences in unemployment rates across demographic groups are accompanied by similar differences in mean unemployment duration and long-term unemployment shares, although the relationship between these variables is not particularly tight. For example, on average the mean unemployment duration of older workers is more than twice the mean duration of younger workers, yet the unemployment rate of older workers is less than half that of younger workers. This observation highlights that there are two determinants of unemployment, inflows and outflows, as discussed previously. ${ }^{10}$ The low unemployment

${ }^{8}$ Across race groups, unemployment rates tend to be lower among whites, but relative to the whole sample unemployment rates among whites increased in 2010. One should be careful when comparing the unemployment rate changes of different race groups since the sample periods do not coincide.

${ }^{9}$ The occupation and industry affiliation of an unemployed worker refer to the last job held by that worker. It is not uncommon for workers to change occupations or industries, even without an intervening unemployment spell. The classification of an unemployed worker by last known employment can be useful if it reflects on the human capital that an unemployed worker has acquired and that affects the job search decisions of that worker.

${ }^{10}$ See also the discussion of unemployment in OECD countries in Box 2. 
rate for older workers, then, is mainly due to a very low inflow rate into unemployment - in other words, a very low probability of losing a job. On the other hand, once an older worker loses a job and becomes unemployed, the probability of finding a new job is very low compared to a younger worker. Nevertheless, it appears as if a general decline in job finding rates was an important driver of the increased unemployment rate in the 2007-09 recession. Across all demographic groups, there are comparable increases in mean unemployment duration and long-term unemployment shares in 2010.

We have documented differences in the way unemployment rates, mean duration, and long-term unemployment changed for different demographic groups, but we do not want to overemphasize these differences since essentially all groups experienced significant increases in unemployment. A more thorough analysis of the role of demographic changes and their contributions to the average duration of unemployment is provided by Aaronson et al. (2010). They compare average unemployment duration in (1) the expansion phases following the 1981-82 and the 2001 recessions, and in (2) the first six months following the 1981-82 and the 2007-09 recessions. To a first approximation, Aaronson et al. (2010) calculate the change in total unemployment that is attributable to two different factors. First, they calculate the change in unemployment duration that would have occurred given the change in the demographic composition of the labor force, but assuming that the unemployment durations within demographic groups do not change. Second, they calculate the change in unemployment duration that would have occurred assuming no change in the demographic composition of the labor force, but allowing for the observed change of unemployment durations within demographic groups. ${ }^{11}$ They find that comparing the expansion phases after the 1981-82 and 2007-09 recessions, changes in the labor force composition account for less than half of the trend change in unemployment duration. Furthermore, comparing the periods immediately after the 1981-82 and 2007-09 recessions, changes in the labor force account for only one-fifth of the difference in unemployment duration.

\footnotetext{
${ }^{11}$ There is also a third effect, which captures any interactions between changes in the relative size of demographic groups and changes in durations within demographic groups.
} 


\section{DURATION DEPENDENCE OF UNEMPLOYMENT}

People are different, and survey measures do not capture all the characteristics that are relevant to unemployment duration. Some characteristics that are relevant to the chances of an unemployed worker finding work can be quite persistent yet unobservable, and these characteristics might actually be related to the unemployment experience itself. For example, consider two equal pools of unemployed workers who at the beginning of the month share the same observable characteristics, except for the time that they have been unemployed already. On average, at the end of the month relatively more workers from the pool with the shorter unemployment duration will have found work. In other words, the longer a worker has been unemployed already, the less likely it is that he or she will find a job. This apparent decline in exit rates with the length of time unemployed is called "negative duration dependence." 12

Negative duration dependence is clearly inconsistent with the simple model of homogeneous unemployment that we discussed previously, since that model assumes that in any given month all unemployed workers have the same chance of finding work, independent of how long they already have been unemployed. This observation may account for the fact that the simple model understates the prevalence of long-term unemployment.

As noted previously, we can use the entry and exit rates from our unemployment accounting exercise to construct counterfactual duration distributions for unemployment. When we account for unemployment in the previous section, we use the share of workers who were unemployed for fewer than 5 weeks to calculate estimates of the exit rate from unemployment. Suppose we were instead to use the share of workers who were unemployed for fewer than 15 weeks to calculate the exit rate from unemployment. The simple model imposes the same exit rate on workers who were unemployed for fewer than 5 weeks and on workers who were unemployed for between 5 and 15 weeks.

But if there is negative duration dependence, the exit rate we calculate when we use the share of workers who have been unemployed for fewer than 15 weeks should be less than the exit rate we calculate when we use the share of workers who have been unemployed for fewer than 5 weeks. In Figure 2 we display the exit rates from unemployment based on different segments of the duration distribution of

${ }^{12}$ See Machin and Manning (1999) for a survey on the role of duration dependence in the determination of long-term unemployment in Europe. 
unemployment: the share of workers who have been unemployed for fewer than 5 weeks, fewer than 15 weeks, and fewer than 27 weeks. In fact, consistent with negative duration dependence, the implied exit rates decline monotonically as unemployment duration increases.

Two explanations have been proposed for the observed negative duration dependence of exit rates from unemployment. The first explanation simply assumes that for each unemployed worker, the exit rate is a declining function of elapsed unemployment duration. Then the exit rate from the unemployment pool declines with the duration that the pool's members have been unemployed. This approach is called "true duration dependence." An alternative explanation is to assume that newly unemployed workers already differ according to their exit rates from unemployment. Even if the exit rate for an individual worker does not change over time, the composition of the pool will change over time, which implies a change in the average exit rate from the pool. In particular, over time workers with a high exit rate will make up a smaller and smaller share of the remaining pool of workers who have not yet found work, which implies a declining average exit rate from the pool. This approach is called "unobserved heterogeneity."

Various reasons can account for true duration dependence in exit rates. For one, over time unemployed workers tend to lose skills associated with actual work experience and work-related training. This decline in human capital implies that the average wage offer an unemployed worker could obtain probably also would decline over time.

If the benefits of staying unemployed remain constant over time, for example via constant unemployment insurance payments, while the average wage offer is declining, then the likelihood that an unemployed worker accepts an offer probably also declines over time, and so would the exit rate. Additionally, over time unemployed workers lose attachment to networks that may aid in finding new jobs. Finally, potential employers might interpret a prolonged unemployment spell as a signal of ability, irrespective of the true, underlying characteristics of the unemployed worker. All of this means that exit rates from unemployment would decline over time. ${ }^{13}$

Unobserved heterogeneity does not need any particular story. Clearly surveys do not capture all the information that is relevant to the determination of exit rates from unemployment. For example, a worker who loses a job for reasons that are idiosyncratic to the previous employer

\footnotetext{
${ }^{13}$ See Ljungqvist and Sargent (1998) for an example that studies the implications of duration dependence due to human capital depreciation. See Blanchard and Diamond (1994) for an example of duration dependence due to employer screening of long-term unemployed.
} 
may have skills that are valued by a wide range of employers, and may find work relatively quickly. On the other hand, if a worker loses a job in an industry or occupation that is in secular decline, the skills of that worker may not be easily transferable to a wide range of employers, and this worker may stay unemployed for a long time.

The two explanations of duration dependence potentially have different policy implications. If true duration dependence is widespread among unemployed workers, then current high levels of unemployment might imply high future unemployment because more unemployed workers make the transition to long-term unemployment. In this case, a reduction in current unemployment, if possible, would reduce future unemployment. On the other hand, if unobserved heterogeneity accounts for duration dependence and the increase in unemployment, and the duration of unemployment is mainly due to an influx of workers with low exit rates, it might be a signal that unemployment is due to a "mismatch" of skills. In this case, high unemployment may reflect structural change and may not be amenable to monetary policy actions.

Preliminary work by one of the authors of this essay indicates that a simple framework with two types of unemployed workers - short-term unemployed with a relatively high exit rate from unemployment and long-term unemployed with a relatively low exit rate - can account quite well for the observed variation in the duration distribution of unemployment (Hornstein 2011). This framework allows for two special cases. The first case consists only of true duration dependence: all unemployed workers are initially short-term unemployed with a high exit rate from unemployment, but during unemployment workers make a random transition from short-term to long-term unemployment. The second case consists only of unobserved heterogeneity: workers are from the beginning either short-term or long-term unemployed, and they never change types.

The two special cases of the framework provide different accounts of unemployment volatility. In the true duration dependence case, almost all of the unemployment rate fluctuations are attributed to exit rate fluctuations of the two types. Changes in entry rates of short-term unemployed workers and transition rates from short-term to long-term unemployment - that is, the true duration mechanism itself-have only a limited effect. In the unobserved heterogeneity case, on the other hand, a substantial portion of the unemployment rate fluctuation is attributable to changes in the entry rate of long-term unemployed workers. In this case, fluctuations in entry and exit rates of long-term unemployed workers account for about two-thirds of unemployment rate 
volatility. Of the two cases, the unobserved heterogeneity approach provides a better match to the unemployment duration distribution.

The more general framework that allows for both true duration dependence and unobserved heterogeneity yields results that are closer to the special case of only unobserved heterogeneity. In the general framework, unemployment volatility is about equally accounted for by changes in the entry rate of long-term unemployed workers and the exit rates of both types. Furthermore, it appears as if the observed increase in unemployment in the 2007-09 recession is mainly driven by the increased entry rate and reduced exit rate of long-term unemployed workers. ${ }^{14}$ Given the above interpretation of long-term unemployment due to unobserved heterogeneity, one could then argue that most of the increase in unemployment in the 2007-09 recession represents an increase in structural unemployment.

\section{LONG-TERM UNEMPLOYMENT AND MONETARY POLICY}

A simple view of the statistical relationship between unemployment and inflation - the Phillips curve - suggests that the choices for monetary policymakers who want to promote employment and price stability are clear. Unemployment is high and inflation is low, therefore monetary policy can and should be expansionary. Yet many modern macroeconomists argue that movements in real quantities matter for inflation dynamics only to the extent that they depart from their natural level. Furthermore, the best way to attain low unemployment volatility in the long run is to follow policy rules that promote price stability. ${ }^{15}$ In this view, the labor market situation in the wake of the Great Recession still presents a challenge to monetary policymakers.

Macroeconomic theory defines the natural rate of unemployment as the hypothetical level of unemployment that would obtain in the absence of any distortions, such as impediments to free adjustment of nominal prices and wages. The difference between actual and natural unemployment is often referred to as the "unemployment gap." It constitutes a measure of the degree of slack, or under-utilization of resources, in the economy; a large and positive unemployment gap may constrain inflationary pressures. With a large pool of unemployed workers to hire from, wages are unlikely to increase, which therefore

\footnotetext{
14 According to the more general framework, the behavior of unemployment in the 2007-09 recession is similar to its behavior in the 1981-82 recession. It is unlike the 1973-75 and 1990-91 recessions, where the increase in the unemployment rate was mainly driven by a general decline in exit rates.

${ }^{15}$ For one exposition of this view, see Lacker and Weinberg (2006).
} 
limits pricing pressures stemming from rising input costs. This scenario seemingly describes the recent economic climate, with unemployment persistently high and inflation trending gradually lower over the course of the recession. How useful this argument is for policy decisions depends on how easy it is for policymakers to discern the level of the natural rate. A main point of contention in the current policy debate is whether the natural rate has substantially shifted upward over the course of the Great Recession. The existence of very high long-term unemployment has implications for this debate.

We have shown that the prevalence of long-term unemployment is related to the fact that the exit rate out of unemployment declines with the duration of unemployment. Since a high fraction of long-term unemployed workers find it difficult to transition to employment, the pool of workers who can reasonably expect to be hired may be effectively smaller than it appears from the raw unemployment numbers alone. Thus the natural rate of unemployment would be higher, and the unemployment gap smaller, than what one might infer from the measured level of unemployment. Furthermore, a preliminary account of unemployment during the Great Recession seems to indicate that overall unemployment increased because of increased entry rates and reduced exit rates of long-term unemployed workers, suggesting that structural unemployment, and therefore the natural rate of unemployment, has increased.

How, then, should monetary policymakers respond to the increase in long-term unemployment? To the extent that the exceptionally large share of long-term unemployment reflects structural change and a higher natural rate of unemployment, policymakers should seriously consider the possibility that a high unemployment rate does not necessarily equate to a large unemployment gap. Furthermore, if higher long-term unemployment were to become a permanent feature of the U.S. labor market, then the level of unemployment would be even less likely to respond to short-term monetary stimulus. Any policy options to deal with permanent long-term unemployment would likely have to take the form of structural labor and product market reforms that increase the ability and willingness of the unemployed to find work, and reduce the costs of generating and maintaining employment relationships. Reforms of this kind arguably reduced the incidence of long-term unemployment in, for instance, the United Kingdom in the 1980s and Germany during the past decade. 


\section{APPENDIX}

The following sections appeared as Box 1 and Box 2 in the original article.

\section{A SIMPLE FRAMEWORK FOR UNEMPLOYMENT ACCOUNTING}

We can formalize the bathtub model of unemployment described in the text as follows. The labor force consists of a fixed number of $L$ workers who are either employed, $E$, or unemployed, $U$, and $L=E+U$. For simplicity assume that employed workers become unemployed at a constant rate $\sigma$ and that unemployed workers become employed at a constant rate $\lambda$. Then the rate of change of unemployment, $\dot{U}$, is simply the difference between inflows and outflows,

$$
\dot{U}=\sigma E-\lambda U
$$

Inflows and outflows and the change in unemployment are to be interpreted as occurring instantaneously. The unemployment rate is $u=\frac{U}{L}$ and the employment rate is $e=\frac{E}{L}=1-u$. The rate of change of the unemployment rate is

$$
\dot{u}=\sigma(1-u)-\lambda u .
$$

Inflow and outflow rates may change over time, but if these rates remain constant, unemployment will converge to a rest point or steady state, $u^{*}$. If inflows exceed (fall short of) outflows, the unemployment rate will increase (decline), $\dot{u}>0(\dot{u}<0)$, toward the steady state. In the steady state, inflows and outflows just balance such that the unemployment rate remains constant, $\dot{u}=0$,

$$
u^{*}=\frac{\sigma}{\sigma+\lambda} .
$$

If the exit rate from unemployment is large relative to the inflow into unemployment, convergence to the steady state will be fast. In this case, not much is lost in thinking about unemployment in any given month as steady state unemployment corresponding to the inflow and outflow rates for that month, and ignoring the convergence to the steady state.

This simple model assumes that every unemployed worker faces the same chance of exiting the unemployment pool. In particular, this 
exit rate is independent of the time the worker has been unemployed. Again, assuming that the inflow and outflow rates remain unchanged, we can calculate the implied duration distribution of unemployment in the steady state. The share of unemployed workers who have been unemployed for no more than duration $T$ is then given by

$$
\omega_{T}^{*}=1-e^{-\lambda T} .
$$

Entry and exit rates in U.S. unemployment are indeed quite high, and we can interpret unemployment and the duration distribution of unemployment as being close to their steady states. In the text we use data on the duration distribution to recover estimates of the exit rate from unemployment. Given an estimate of the exit rate, we then use data on unemployment to obtain estimates of the entry rate into unemployment.

Another way to relate the exit rate from unemployment to observables is to consider its implications for the average duration of unemployment. Our description of the outflows from unemploymentthat an unemployed worker becomes employed at the instantaneous rate $\lambda$ independent of how long that worker has been unemployedcorresponds to a particular stochastic process, namely a Poisson process. For such a process the average duration that a worker is unemployed is simply the inverse of the exit rate,

$$
\bar{T}=\frac{1}{\lambda} .
$$

The relationship between the exit rate from unemployment and the average duration of unemployment allows us to obtain a back of the envelope calculation of the effect of extended unemployment benefits on the unemployment rate. Suppose that an extension of the length of unemployment benefits increases the average duration of unemployment from $T_{0}$ to $T_{1}$. That implies a reduction in the exit rate from unemployment from $\lambda_{0}=\frac{1}{T_{0}}$ to $\lambda_{1}=\frac{1}{T_{1}}$. Everything else the same, that is, with no change in the separation rate, the steady state unemployment rate increases from $u_{0}=\frac{\sigma}{\left(\sigma+1 / T_{0}\right)}$ to $u_{1}=\frac{\sigma}{\left(\sigma+1 / T_{1}\right)}$.

\section{THE PERSISTENCE OF LONG-TERM UNEMPLOYMENT: AN INTERNATIONAL COMPARISON}

Many European economies experienced high rates of unemployment associated with significant long-term unemployment throughout the 
1980s and 1990s. ${ }^{16}$ This high European unemployment has been attributed to the interaction of labor market institutions with structural and monetary shocks. For example, one of the authors of this essay (Hornstein), together with Per Krusell and Giovanni Violante (2007), argues that in response to a common acceleration of embodied technological change, different labor market institutions in continental Europe and the United States led to a differential response of unemployment and wage inequality in these countries. On the other hand, Laurence Ball (1997) sees the original common shock in a series of disinflations induced by monetary policy around 1980, but also argues that the impact on unemployment differed depending on the countries' labor market institutions. European unemployment rates eventually declined, in some countries arguably due to structural reforms in product and labor markets in the wake of the European Monetary Union.

In the following discussion we provide a short summary of the determinants of unemployment in OECD countries based on the data set provided by Michael Elsby, Bart Hobijn, and AyŞegül Şahin (2011). In our analysis of cyclical long-term unemployment in the United States, we have suggested that a general decline in exit rates from unemployment is an important source of increased long-term unemployment following a recession. The cross-sectional data for the OECD countries, on the other hand, suggest that both entry rates and exit rates are important drivers of unemployment in the long run. Based on the analysis of the simple model in Box 1, we construct job finding rates using the fraction of workers who have been unemployed for fewer than three months. ${ }^{17}$ Using this exit rate from unemployment and the unemployment rate, we construct job separation rates. We construct job finding and job separation rates for each country for each available year. In Figure 3 we display the average job finding and job separation rates for each country. We express these rates as the probability that in any month an employed (unemployed) worker will become unemployed (employed).

\footnotetext{
${ }^{16}$ For a survey, see Machin and Manning (1999).

17 Our procedure assumes (1) that the country data for unemployment rates and duration distributions reflect steady states, and (2) that there is no duration dependence in exit rates from unemployment. The steady state assumption is a good approximation for labor markets with relatively high job finding rates, such as the U.S. labor market. Since the job finding rates are much smaller for almost all other OECD countries, our procedure is potentially less reliable for these countries. It turns out that our estimates from the simple steady-state-based procedure are not that different from the estimates one obtains if transition dynamics are taken into account. Elsby et al. (2011) argue that for most of the continental European countries, there is no significant evidence for duration dependence in exit rates, but that there is evidence for duration dependence in most of the other countries.
} 


\section{Figure 3 Labor Market Turnover in Selected OECD Countries}

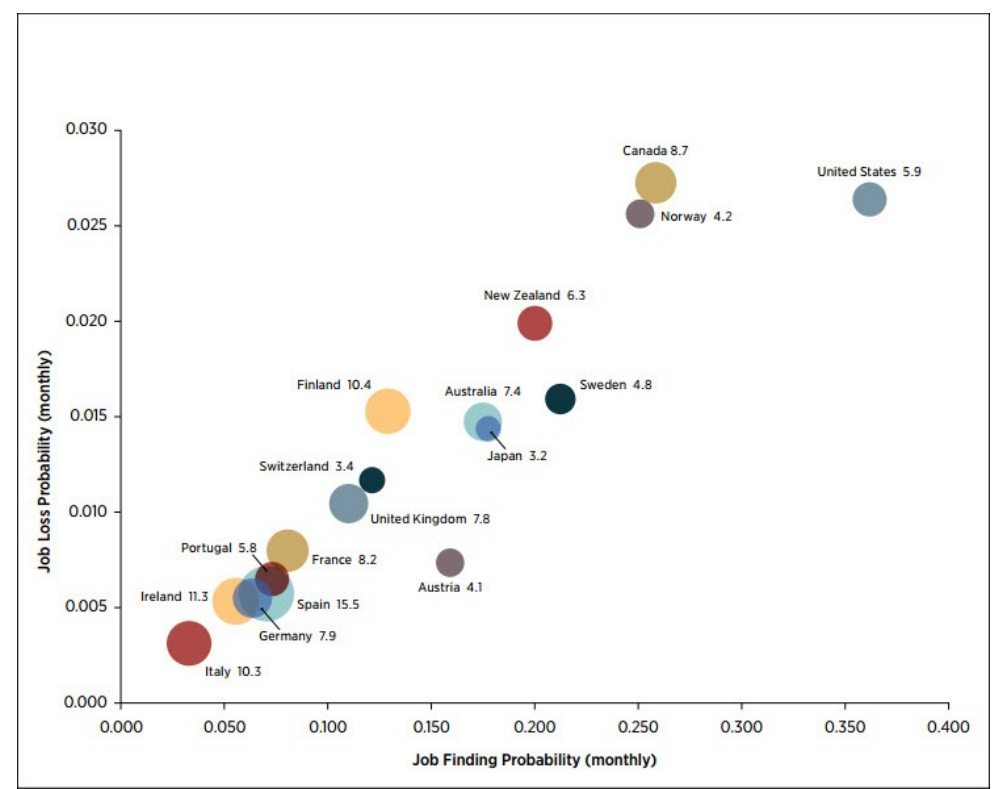

Sources: Elsby, Hobijn, and Şahin (2011), OECD, authors' calculations.

Notes: The number to the right of each country name is the average unemployment rate from 1968-2006. U.S. workers on average are more likely to become unemployed than in other OECD countries, but they also find new work more quickly. In countries with low job turnover, such as Italy and Spain, the average unemployment rate is much higher than in the United States. The number to the right of each country is the country's average unemployment rate from 1968-2006.

The fluidity of the U.S. labor market stands out when compared to the labor markets of almost all other countries. This is especially true when compared to several continental European countries that have high unemployment rates. In the United States, the average unemployed worker has a more than 35 percent chance of finding work within a month, while at the same time there is a less than 3 percent chance that a worker becomes unemployed within a month. The high job finding rate more than counteracts the high job separation rate, such that at 6 percent the average U.S. unemployment rate is quite low compared to most other countries. The Italian labor market, on the other hand, displays very low turnover. Workers rarely become unemployed and unemployed workers take a very long time to find work; job 
separation and job finding probabilities are one-tenth of those in the United States. In Italy this extremely sclerotic labor market results in an unemployment rate that is almost twice that of the United States.

Looking at the cross-section of countries in Figure 3, it appears that the less turnover there is in a country's labor market, the higher the unemployment rate. Most of the continental European countries with high average unemployment rates are concentrated in the lower left hand corner of Figure 3, with low job finding and job separation probabilities. One should be careful not to draw too many conclusions from this observation about the causality between transition rates and the level of unemployment, but there is evidence that low separation rates due to rigid labor market laws can lead to low job finding rates. (For example, see Giuseppe Bertola and Andrea Ichino [1995].) Finally, comparing Figures 2 and 3 we can see that the U.S. job finding rate, even at an extreme cyclical trough like the one after the 2007-09 recession, is still higher than the average job finding rate in most other OECD countries.

\section{REFERENCES}

Aaronson, Daniel, Bhashkar Mazumder, and Shani Schechter. 2010. "What Is Behind the Rise in Long-Term Unemployment?" Federal Reserve Bank of Chicago Economic Perspectives 34 (2): 28-51.

Ball, Laurence M. 1997. "Disinflation and the NAIRU." In Reducing Inflation: Motivation and Strategy, edited by Christina Romer and David Romer, 167-94. Chicago: University of Chicago Press.

Bertola, Giuseppe, and Andrea Ichino. 1995. "Wage Inequality and Unemployment: United States versus Europe." In NBER Macroeconomics Annual, edited by Ben S. Bernanke and Julio J. Rotemberg, 13-66. Boston: MIT Press.

Blanchard, Olivier Jean, and Peter A. Diamond. 1994. "Ranking, Unemployment Duration, and Wages." Review of Economic Studies 61 (3): 417-34.

Elsby, Michael W. L., Bart Hobijn, and AyŞegül Şahin. 2010. "The Labor Market in the Great Recession." Brookings Papers on Economic Activity Spring: 1-48. 
Elsby, Michael W. L., Bart Hobijn, and AyŞegül Şahin. 2011. "Unemployment Dynamics in the OECD." Federal Reserve Bank of San Francisco Working Paper 2009-04.

Elsby, Michael W. L., Ryan Michaels, and Gary Solon. 2009. "The Ins and Outs of Cyclical Unemployment." American Economic Journal: Macroeconomics 1 (1): 84-110.

Fujita, Shigeru, and Garey Ramey. 2009. "The Cyclicality of Separation and Job Finding Rates." International Economic Review 50 (2): 415-30.

Hornstein, Andreas. 2011. "Accounting for Unemployment: The Short and Long of It." Mimeo, Federal Reserve Bank of Richmond.

Hornstein, Andreas, Per Krusell, and Giovanni L. Violante. 2007. "Technology-Policy Interaction in Frictional Labour-Markets." Review of Economic Studies 74 (4): 1,089-124.

Lacker, Jeffrey M., and John A. Weinberg. 2006. "Inflation and Unemployment: A Layperson's Guide to the Phillips Curve." Federal Reserve Bank of Richmond 2006 Annual Report, 4-26.

Ljungqvist, Lars, and Thomas J. Sargent. 1998. "The European Unemployment Dilemma." Journal of Political Economy 106 (3): $514-50$.

Machin, Stephen, and Alan Manning. 1999. "The Causes and Consequences of Longterm Unemployment in Europe." In Handbook of Labor Economics Vol. 3, edited by Orley Ashenfelter and David Card, 3,085-139. Amsterdam: Elsevier.

Mazumder, Bhashkar. 2011. "How Did Unemployment Insurance Extensions Affect the Unemployment Rate in 2008-10?" Federal Reserve Bank of Chicago Chicago Fed Letter no. 285.

Shimer, Robert. 2007. "Reassessing the Ins and Outs of Unemployment." Mimeo, University of Chicago. 